\title{
Laboreal
}

Volume $12 \mathrm{~N}^{\circ} 1$ | 2016

Os Equipamentos de Proteção Individual (EPI):

protetores, mas nem sempre

\section{Os usos do corpo-si no trabalho de transformação de granitos: evidências para saúde e segurança}

Los usos del cuerpo-sí en el procesamiento de granito: evidencias para la seguridad y la salud

Les usages du corps-soi dans le travail de transformation du granit: évidences du point de vue de la santé et de la sécurité

The uses of corps-soi ("body-oneself") in granite transformation work: evidence for health and safety

Thiara De Ângeli Porto e Mônica de Fatima Bianco

\section{OpenEdition}

\section{Journals}

\section{Edição electrónica}

URL: http://journals.openedition.org/laboreal/3053

DOI: 10.4000/laboreal.3053

ISSN: 1646-5237

\section{Editora}

Universidade do Porto

\section{Refêrencia eletrónica}

Thiara De Ângeli Porto e Mônica de Fatima Bianco, « Os usos do corpo-si no trabalho de

transformação de granitos: evidências para saúde e segurança », Laboreal [Online], Volume $12 \mathrm{~N}^{0} 1$

2016, posto online no dia 01 julho 2016, consultado o 08 outubro 2019. URL : http://

journals.openedition.org/laboreal/3053; DOI : 10.4000/laboreal.3053

Este documento foi criado de forma automática no dia 8 outubro 2019

\section{cc) (†) \$}

Laboreal está licenciado com uma Licença Creative Commons - Atribuição-NãoComercial 4.0 Internacional. 


\section{Os usos do corpo-si no trabalho de transformação de granitos: evidências para saúde e segurança}

Los usos del cuerpo-sí en el procesamiento de granito: evidencias para la seguridad y la salud

Les usages du corps-soi dans le travail de transformation du granit: évidences $d u$ point de vue de la santé et de la sécurité

The uses of corps-soi ("body-oneself") in granite transformation work: evidence for health and safety

Thiara De Ângeli Porto e Mônica de Fatima Bianco

\section{NOTA DO EDITOR}

http://dx.doi.org/10.15667/laborealxii0116tap

Manuscrito recebido em: março/2016

Aceite após peritagem: junho/2016

\section{Introdução}

1 O trabalho humano constitui-se numa relação dialética entre técnica e ação humana, exigindo a compreensão do trabalho real, mas sobretudo o que transparece do seu poder transformador se considerarmos os usos de si por si e pelos outros nos coletivos de trabalho (Schwartz, 2011a).

2 Em busca de entender junto aos trabalhadores engajados nos processos de beneficiamento de granitos, os "riscos por", referindo-se aos fatores externos, e "riscos de", referindo-se às doenças, e toxidades do meio para se viver ou sobreviver no trabalho, o conceito de "usos do corpo-si" se fez, efetivamente, relevante. Este auxilia 
na compreensão da história de cada um, situação a situação, no agir coletivo ligado à história política e social, e ao que há de imprevisível no trabalho, incluindo riscos do trabalho por escolha coletiva decorrentes do viver junto, isto é, trabalhar coletivamente (Schwartz, 2014b).

Desse modo, o intuito do estudo que aqui se apresenta é tratar de trabalho e saúde nos processos de umidificação no beneficiamento de granitos, isto é, do controle da poeira através da utilização da água, utilização esta inicialmente entendida como um Equipamento de Proteção Coletiva - EPC [1], que juntamente com o Equipamento de Proteção Individual - EPI contribuem para manutenção da saúde e segurança do trabalhador. $\mathrm{O}$ estudo está vinculado a um trabalho académico. Também faz parte de uma pesquisa, mais abrangente, para compreender melhor o trabalho real em diferentes organizações de beneficiamento de granitos no estado do Espírito Santo Brasil, que fazem um uso intenso da atividade humana nos processos de trabalho.

4 Trata-se de uma pesquisa qualitativa e descritiva das situações de trabalho, embora perspetivada sob o ponto de vista da atividade humana, permeada das singularidades daqueles que a realizam. Optou-se pela cartografia (Deleuze \& Guattari, 1995) para abordagem do campo, por sua proposta metodológica de acompanhar os processos de caráter dinâmico, como as situações de trabalho o são. Complementarmente, o referencial teórico da ergologia sustentou a nossa preocupação em melhor compreender os usos de si por si e pelos outros, os usos do corpo-si e as renormalizações nos processos de umidificação para promoção da saúde e segurança, no beneficiamento de granitos.

5 Para tanto, este artigo está organizado da seguinte maneira: trata da abordagem Ergológica; apresenta aspectos econômicos e situacionais do Setor de Rochas Ornamentais; os aspectos metodológicos são apontados, incluindo uma breve apresentação da organização locus do estudo, a descrição da abordagem do campo embasada por princípios da cartografia, o modo com os dados foram tratados no estudo e depois apresentados na análise e discussão de dados, e por fim tece as considerações finais.

\section{A abordagem ergológica}

6 A abordagem ergológica sustenta a importância de uma análise do trabalho que apreenda a dialética entre o que se passa a um nível micro e a um nível macro de análise. Especificamente, o estudo do trabalho em seu nível micro, como se se fizesse sob uma lupa, a partir da atividade de trabalho com suas singularidades, e gestão das situações, o "agir conjunto" da produção material e imaterial, incorpora as contradições que trazem todo sujeito da atividade industriosa, as contradições entre os usos de si por si e pelos outros (Schwartz, 2014a).

7 O uso de si por si se refere ao posicionamento que cada trabalhador toma diante das normas com as quais se depara revelando compromissos microgestionários, confrontando-as e alterando-as, recombinando valores e critérios na busca por uma adequação à sua "realidade", tornando cada ato de trabalho único; enquanto o uso de si pelos outros remete a um conjunto de regulamentos diversos, visto que jamais se trabalha totalmente sozinho, mas com colegas de trabalho ou com pessoas não próximas (Schwartz, 2004; Schwartz; Duc \& Durrive, 2010a). 
8 Na perspectiva ergológica, há o movimento entre os polos do saber da prática e os do saber conceitual; empreendidos por um terceiro polo ético-epistemológico, o qual direciona o desenvolvimento de diálogo para os valores para a valorização da cidadania, da ética da vida, da saúde e da igualdade (Schwartz, 2000; Moraes \& Pinto, 2011). Nessa relação, é preciso respeitar o ponto de vista da atividade (Moraes \& Pinto, 2011).

$\mathrm{Na}$ atividade de trabalho, há sempre uma parte antecipável, visto que toda situação de trabalho é sempre aplicação de um protocolo, e outra parte inantecipável. No uso de si por si e no uso de si pelos outros há a reinvenção da maneira de ser, de viver, de sobreviver. Isso porque os indivíduos são únicos e singulares, viventes de histórias e experiências únicas que refletem e interferem na realização de suas atividades, mesmo que em certas profissões haja normas bem precisas, elas sempre serão insuficientes, devido a certos "vazios de normas" (Schwartz, 2010a), de fato inevitáveis pela parte enigmática do trabalho que não pode ser antecipável. Essa dimensão invisível do trabalho resulta nas arbitragens, "renormalizações", mesmo que ínfimas (Schwartz, 2014b).

10 Em meio a esses embates de normas, os sujeitos captam informações in situ que favorecem as arbitragens industriosas, e em parte, reconfiguram as condições do engajamento industrioso a partir da presença do corpo que sente, vigia, adere e seleciona parâmetros variáveis da situação em que não há domínios definidos e circunscritos, mas uma síntese, denominada de "corpo-si" (Schwartz, 2014a; 2014b).

O corpo-si é [...] o elemento que cria e se cria em cada experiência singular que os limites da prescrição lhe colocam. Trata-se de um elemento de transgressão que não se afirma pela mera desobediência às normas, mas, sobretudo, por afirmar, por meio da potência de produção do mundo, a capacidade de inventar novas normas de fazer coisas e de viver a vida (Moraes \& Pinto, 2011, p. 284).

11 A expressão corpo-si designa o que foi moldado por experiências, saberes e histórias e tenta explicar o fato de que as "renormalizações", isto é, as tentativas individuais e coletivas de retrabalho das normas antecedentes da atividade, não concernem somente ao corpo, a vida psíquica, política e cultural, mas a uma sinergia de todas as dimensões do ser (Schwartz, 1998; 2014b). Essa sinergia corresponde ao trabalho, a seu uso, e uma vez diante de situações jamais padronizadas na atividade industriosa individual e coletiva, o uso no trabalho por si e pelos outros se faz constante, sendo denominado por Schwartz de usos do corpo-si (Schwartz, 2014b), como uma evolução do conceito de dramáticas do uso de si : "cremos poder afirmar que o trabalho como uso de si é uso de um corpo-si" (Schwartz, 2014a, p. 263).

12 A pessoa que executa uma atividade - na opinião de Moraes e Pinto (2011) ao estudarem o uso do corpo-si -, é mobilizada, por inteiro, para inventar e gerir saídas para as situações reais. Ou seja, "mais que decisões mentais, ela se engaja por inteiro, com todas as dimensões em jogo (corporal, social, cognitivo, afetivo) para encontrar os meios de resolver as situações" (Moraes \& Pinto, 2011, p. 284).

13 Diz-se, a atividade de trabalho é sempre um destino a se viver, um "encontro histórico" entre os saberes acumulados nas técnicas, nos coletivos e o saber da prática, da experiência. $\mathrm{O}$ uso de si está na imposição contínua de micro escolhas permanente, vivenciando a dramática, com as escolhas e os riscos que a envolvem (Schwartz, Duc \& 
Durrive, 2010b). Em meio a essas escolhas e riscos, o corpo biológico e pensante passa por reajustes como um esforço de vida, que cria e se recria em meio à atividade.

Assim, a análise ergológica é feita tanto quanto possível do ponto de vista da atividade, concentrando-se sobre a relação das pessoas com o meio no qual estão engajados (Schwartz et al., 2010b), com o intuito de investigar o permanente debate de normas e de valores que renovam indefinidamente a atividade humana. Isto é, a dimensão enigmática da atividade e a relação entre trabalho e saúde, destacando-se que "o trabalho não é apenas fonte de doença e infelicidade, podendo ser também, ao contrário, operador de saúde e prazer" (Neves, Athayde \& Muniz, 2004, p. 305).

Em se tratando do desejo de saúde e das singularidades do trabalho, Yves Schwartz retoma então Canguilhem (1947; 1994; 1995). Todo homem deseja ser sujeito de suas normas, de modo que "viver é irradiar" (Canguilhem, 1947), isto é, viver é organizar o meio em função da avaliação, da valorização e das decisões de si em relação a seu próprio agir, uma vez que, saúde diz respeito à capacidade e necessidade de criar normas e viver de acordo com elas (Canguilhem, 1995).

\section{0 setor de rochas ornamentais: aspectos econômicos e situacionais}

\subsection{Aspectos de relevância econômica}

Tendo como base a concepção de trabalho como atividade humana e de gestão como uso das singularidades na ação, a delimitação do campo seguiu também critérios como: a relevância social e econômica do setor para o estado do Espírito Santo. Nesse sentido, a escolha do setor se deu pelo fato do Brasil possuir inúmeros recursos naturais, dentre eles uma grande quantidade de Rochas Ornamentais. $O$ setor de rochas ornamentais gera cerca de 120 mil empregos (entre diretos e indiretos) no país, a partir de 10.000 empresas atuando no setor, como: pedreiras, de beneficiamento, marmoraria e moageiras (Chiodi, 2015). O Estado do Espírito Santo [2] responde por $80 \%$ das exportações realizadas pelo país, representando venda de mais de 1,8 milhão de toneladas de rochas para o mundo, em 2014 exportou um montante de 1,08 bilhão de dólares, em termos econômicos (Vitoriastonefair, 2015), o que correspondeu a cerca de 7\% do Produto Interno Bruto (PIB) do estado do Espírito Santo (Ayub et al., 2014).

No entanto, apesar da relevância econômica do setor a mesma projeção positiva não ocorre com o lado social, composto por uma realidade problemática no que diz respeito à gestão, em especial a gestão de pessoas e políticas de saúde e segurança. Estudos recentes mostram que os trabalhadores do setor, em especial do beneficiamento, adquirem sua formação no dia-a-dia de trabalho ao longo de sua vida profissional, além de executarem trabalhos multifuncionais - necessários pelos sistemáticos cortes em mão de obra direta, em paralelo a escassos investimentos na mão-de-obra tanto em relação à qualificação quanto em termos salariais (Mezadre, 2013). 


\subsection{Aspectos situacionais, doenças ocupacionais ligadas ao trabalho}

Nesse estudo o recorte de investigação escolhido deu ênfase às doenças ocupacionais, à saúde no trabalho presentes e correlacionadas aos processos de umidificação no setor.

A preocupação com a saúde e a segurança do trabalhador no setor de Rochas Ornamentais tem crescido, assim como também a conscientização de empregadores e empregados, que vêm buscando respeitar as regulamentações implementando as mudanças necessárias. Dentre as doenças relacionadas ao trabalho na mineração, como as doenças de pele; por esforço repetitivo; as respiratórias, como a silicose, merecem destaque, não apenas pela grande prevalência, mas principalmente pela gravidade potencial dos seus quadros, dado o caráter irreversível e incurável dessas doenças (Cattabriga \& Castro, 2013; Mendes, 2014).

A sílica corresponde a um mineral que existe em grande quantidade na forma cristalina, e está presente na maioria das rochas. É encontrada na poeira mineral, causando silicose por inalação dessa poeira e fixação das partículas de sílica nos pulmões (pneumoconiose), por isso é considerada uma das principais causas de invalidez entre as doenças respiratórias ocupacionais, sendo usual em trabalhadores que estão em contato com a sílica. Além disso, a exposição prolongada dos trabalhadores a esse mineral pode provocar outros tipos de doença pulmonar, como: a obstrutiva crônica, o enfisema e a tuberculose pulmonar, além de câncer no pulmão (Cattabriga \& Castro, 2013).

21 De acordo com o mapa de exposição à sílica no Brasil, a região sudeste é responsável por expor 1.484.585 trabalhadores à poeira de sílica e, destes, o estado do Espírito Santo apresenta maior exposição, com 9\% (Ribeiro, 2010). O granito é o tipo de rocha que contém os maiores teores de sílica, enquanto que, o mármore, geralmente não a contêm; apesar disso, na poeira suspensa no ar os teores de sílica se tornam diferentes dependendo da densidade de cada partícula componente da poeira, e de outros fatores que afetam a dispersão dessas partículas no ar (Santos, Cançado, Anos, Amaral \& Lima, 2007).

Sob o ponto de vista da saúde ocupacional, alguns estudos mostram que a principal medida de prevenção das doenças respiratórias e do controle sobre a geração de poeira no ambiente de trabalho é o processo de umidificação (Mendes, 2014) entendido aqui como Equipamento de Proteção Coletiva - EPC. Nesse sentido, é que está presente na Norma Regulamentadora do Ministério do Trabalho e Emprego para Segurança e Saúde Ocupacional da Mineração 22 (NR22) e na Norma Reguladora de Mineração 9 do Ministério de Minas e Energia para Prevenção contra Poeiras Minerais (NRM 9.1) para controle da geração de poeiras nos postos de trabalho, devido ao risco de doenças respiratórias como a silicose (Gruenzner, 2003; Mendes, 2014).

Além dessas normas, há outras prescrições, como a Norma Regulamentadora 11 (NR 11). Esta discorre sobre todo o processo de transporte, movimentação, armazenagem e manuseio de materiais, isto é, trata da movimentação de chapas com ventosas, cabos de aço, cintas, correias, correntes e garras, dentre outras disposições que são passadas aos trabalhadores no curso sobre a operação de ponte rolante, curso obrigatório para os trabalhadores do beneficiamento de granitos. A Norma Regulamentadora 6 (NR 6) estabelece e define os tipos de Equipamentos de Proteção Individuais - EPI's, que as 
empresas são obrigadas a fornecerem a seus trabalhadores conforme as condições de trabalho, a fim de resguardar a saúde e a segurança dos mesmos.

\section{Aspectos metodológicos da pesquisa}

Esta pesquisa foi realizada com trabalhadores de uma empresa de pequeno porte do setor de rochas ornamentais no ES, logo cabe uma breve apresentação dessa organização, locus do estudo, no primeiro subitem. Seguido de outros dois subitens, o primeiro, com base na postura assumida por um cartógrafo, faz a descrição da abordagem do campo para obtenção dos dados e, o segundo, com o modo como os dados foram tratados no estudo e depois aqui apresentados.

\subsection{A empresa TJ Granitos e seus principais processos}

A organização aqui denominada de TJ Granitos LTDA, atua no seguimento de beneficiamento de Mármores e Granito desde 2002. Seu surgimento decorre da união de duas empresas, que realizavam vendas de Rochas Ornamentais em estado bruto para o mercado externo, isto é, em blocos de pedras. Estas, diante da possibilidade de novos e melhores negócios decidem se unir para potencializar suas vendas através da criação de uma indústria conjunta. Assim, criam a TJ Granitos para atuar no beneficiamento de rochas ornamentais, com as etapas de: serragem, levigamento, resinamento, polimento e classificação, retoque e ovada no contêiner, dos quais apenas três etapas utilizam a água em seus processos, que são: a serragem, o levigamento e o polimento.

A serragem consiste no corte dos blocos de mármore ou granito em chapas de 2 ou 3 centímetros de espessura, utilizando para isso o Multifios, maquinário que realiza o corte com vários fios diamantados, para posteriormente seguirem para ser levigada. 0 levigamento consiste no desbaste das chapas, permitindo que as superfícies fiquem planas e uniformes para receber a resina, utilizando para isso abrasivo que são postos na Levigatriz, maquinário utilizado. $O$ polimento consiste na etapa em que as chapas são polidas com o uso de abrasivos pelo maquinário denominado Politriz, com a finalidade de deixar o material com textura e brilho final. Logo após ter saida da Politriz, cada chapa é medida e classificada como de $1^{\mathrm{a}}, 2^{\mathrm{a}}$ ou $3^{\mathrm{a}}$ qualidade, sendo essa a ordem decrescente de seu valor comercial.

A TJ Granitos desenvolve suas atividades a partir das deliberações de seus dois diretores, um de cada empresa fundadora, com percentual igual na sociedade (50\% para cada), além de dois encarregados: um para a produção e outro para a Gestão de Pessoas, um responsável pela limpeza da área administrativa e trinta e dois (32) trabalhadores atuando na produção, totalizando dois diretores e trinta e cinco (35) empregados. Na produção, dez (10) trabalhadores atuam nos processos a úmido, já explicitados, critério considerado na escolha da organização para o presente estudo.

Para a realização da pesquisa, o objeto e o objetivo da mesma foram apresentados à empresa com o intuito de abordar o trabalho real desenvolvido pelos trabalhadores do beneficiamento a úmido, processo normatizado e relacionado ao tema da saúde e segurança, incluindo a utilização de EPI`s. Os responsáveis pela empresa se mostraram interessados no tema, porém, não formularam expectativas específicas em relação ao estudo, permitindo o acesso as áreas. 


\subsection{Cartografando processos de beneficiamento de granitos}

Uma pesquisa de campo exige que se assuma certa postura para obtenção de dados, neste sentido a cartografia, pode-se dizer, pautou esse processo e, assim como a ergologia, permeou todo o estudo. Como dito, a cartografia se coloca como uma postura ou prática metodológica e foi inicialmente formulada por Deleuze e Guattari (1995). Podemos considerar que acabou por orientar a nossa presença no dia a dia da empresa, tal como o referencial teórico-metodológico da ergonomia da atividade, da psicologia do trabalho ou de algumas tradições da sociologia, vai guiando outros pesquisadores.

Assumimos aqui, que enquanto prática, a cartografia dispõe-se ao desafio de acompanhar processos e não, como o próprio termo podia o deixar entender, de representar um objeto. Com base em diferentes autores (Rolnik, 2006; Kastrup, 2009) e pesquisadores, entende-se que a cartografia tem caráter dinâmico e processual. Esta "se constrói e se atualiza a cada encontro entre sujeito e objeto/ pesquisador e campo de pesquisa" (Binda, 2009, p. 53).

31 Diz-se que o cartógrafo quer estudar a vida em movimento - movimento do desejo, o que não é visível, o imprevisível, e "analisar o processo de constituição de novas realidades" (Binda, 2009, p. 53). Logo, o uso dessa postura, nesta pesquisa entende-se como pertinente, tendo em vista que a atividade de trabalho, na perspectiva Ergológica, é concebida como um enigma a ser perscrutado (Schwartz, 2011b), um ato complexo que engloba para além da execução de tarefas preestabelecidas, uma dialética entre técnica e ação humana que não é completamente antecipável (Durrive \& Schwartz, 2008).

32 A seguir, são indicados aspectos importantes para a construção do estudo no beneficiamento de granitos a úmido, com essas perspectivas teórico-epistemológicas.

\subsubsection{Obtenção dos dados}

33 Nessa pesquisa, acompanhar os processos de trabalho com a combinação entre valores, saberes e atividade, além de outros aspectos singulares presentes nas situações de trabalho se mostrava importante. Esse acompanhamento de encontros, como tratado tanto na cartografia quanto na ergologia, ocorreu a partir de visitas a campo durante cinco meses (julho a novembro de 2015), com a frequência média de duas visitas por semana por cerca de 4 horas seguidas a cada vez, ou seja, num total de 160 horas. A escolha da organização locus da pesquisa foi condicionada a critérios como: ser sediada no estado do Espírito Santo; utilizar maquinário apropriado para processos a úmido umidificação; possibilitar a entrada do pesquisador e a realização de suas atividades; facilidade de acesso por parte do pesquisador. As visitas foram liberadas para ocorrerem sempre no período da tarde, mediante contato telefônico no período da manhã para confirmar a ida da pesquisadora no dia; o que não foi empecilho para o contato com os trabalhadores envolvidos nos processos com umidificação, alguns destes trabalham por escala, uma semana de dia e outra à noite, revezando, como os que atuam na serragem e no polimento.

Tal como em Holz (2014), neste estudo, a prática de fazer perguntas aparentemente simples, de se envolver em conversas despretensiosas durante os momentos de pausa para o lanche, e o mostrar interesse pelo trabalho, foram formas de captar os modos singulares de agir, e os valores que permeavam aquele coletivo. Na condição de mulher 
que habita um ambiente predominantemente masculino, estar implicada significou mais do que vestir-se semelhante a eles, mas impregnar-se pelo campo, seja: no uso ou não dos Equipamentos de Proteção Individual, em respirar o ar carregado de partículas de sílica que eles respiram, em sentir a pele impregnada pela poeira, em sentir coceiras na pele e ficar com os olhos irritados devido aos respingos de água que voam das máquinas, para, na medida do possível, tornar-se um deles. Romper as limitações do linguajar foi essencial para captar e compreender os jargões e expressões coloquiais, que serviram de indicadores de normas sociais que pautam a atividade, possibilitando a compreensão de usos de si por si e pelos outros, ou seja, os usos do corpo-si. Desse modo, habitar esse território, como prevê a cartografia, possibilitou a compreensão de pressupostos centrais da abordagem Ergológica, tomando o trabalho real como elemento central da investigação.

Outros instrumentos utilizados foram entrevistas semiestruturadas e em profundidade, permitindo que o trabalhador verbalizasse sua atividade, a fim de expressar as referências pelas quais se manifestam os valores em que sua atividade se apoia (Duraffourg, Duc \& Durrive, 2010). A partir de um roteiro contendo 44 questões, elaboradas e revistas a partir de observações efetuadas, foram realizadas dez entrevistas com trabalhadores. O critério utilizado para composição do grupo de entrevistados foi atuar em funções do processo de beneficiamento que utilizam a água, isto é, a umidificação. Com isso, foram identificadas tais funções, e foram entrevistados trabalhadores conforme a disponibilidade (liberação do trabalho pelo encarregado), uma vez que as entrevistas ocorreram em horário de trabalho, em local reservado dentro da empresa.

Os nomes dos entrevistados foram substituídos por nomes fictícios escolhidos pelos próprios trabalhadores no ato da entrevista. A realização das entrevistas começou a partir do quarto mês de observação e as mesmas totalizaram cerca de nove horas de gravações, com uma média de 54 minutos cada, sendo todas elas transcritas posteriormente. Seguem algumas características do grupo de trabalhadores entrevistados.

Os participantes diretos eram todos homens com idade entre 20 e 53 anos, cinco deles tinham formação de ensino médio completo, com experiência variando entre 1 ano e 3 meses e 21 anos no setor e, abrangendo todas as funções do beneficiamento na organização.

Quer dizer, todas as funções do processo de beneficiamento que utilizam a umidificação foram contempladas nas entrevistas. As observações em campo, incluindo conversas e anotações em diário, não se restringiram ao grupo de trabalhadores entrevistados, incluindo também os que estavam presentes no período da tarde.

39 A cartografia recomenda à adoção da atenção à espreita, como flutuante, concentrada $\mathrm{e}$ aberta, de modo a utilizar todos os sentidos (Kastrup, 2009). Em geral, o pesquisador dirige sua atenção para algo, tendendo a negligenciar os outros aspectos (Weber, Grisci \& Paulon, 2012). Seguindo também a abordagem ergológica, na análise de situações, não se consegue captar todos os aspectos do trabalho real que envolve vivência, valores, dentre outras situações que permeiam a atividade do sujeito somente pela simples observação.

40 O alerta sobre os cuidados do funcionamento da atenção no trabalho do cartógrafo auxiliou durante o processo de pesquisa, na captura dos valores e sentidos que permeiam as atividades. Ou seja, tal postura auxiliou nas conversas e aproximações com 
os participantes diretos e com os demais trabalhadores, que atuavam no período da tarde durante toda a pesquisa de campo.

41 A cartografia visa às articulações históricas do objeto e suas conexões com o mundo. Assim como a abordagem ergológica centra-se sobre a relação que a pessoa estabelece com o meio em que está engajada, de modo que na tecelagem dos procedimentos se infiltra o inesperado, a história, a vida (Durrive \& Jacques, 2010).

Nesse sentido, escrever um diário de campo também serviu para auxiliar no processo de pesquisa. Foram então feitos relatos regulares após as visitas, que reúnem informações objetivas e impressões que emergiram no encontro com o campo, contendo associações que ocorreram ao pesquisador durante a observação ou quando o relato estava sendo elaborado. Essa prática contribui na captura e expressão daquilo que acontece no campo, das muitas falas e sensações que se apresentam nessa processualidade.

43 A dissolução do ponto de vista do observador é outro exercício constante, praticado ao se cartografar situações de trabalho que são sempre ancoradas em saberes imanentes à atividade, no tempo presente e em valores. Na produção de dados, a análise de todo o material transcrito foi realizada levando em consideração que a ergologia é uma abordagem pluridisciplinar, uma disciplina do pensamento, que tem por intuito convocar e confrontar os saberes acadêmicos com os saberes imanentes à atividade de trabalho. Podemos dizer que foi adotada uma "postura de desconforto intelectual", para dar corpo aos saberes ocultos na atividade, uma vez que a finalidade não é só a de constatar a complexidade nas situações de trabalho, mas a de verbalizar a experiência (Durrive, 2010).

\subsection{Tratamento dos dados obtidos em todo o processo de pesquisa}

Para o tratamento dos dados, recorremos aos principios fundamentais da análise de conteúdo (Bardin, 2006), podendo ser os procedimentos de análise descritos pelo processo de categorização, à posteriori, de modo que após a transcrição das entrevistas e digitação do diário de campo, o critério de categorização utilizado foi o semântico, com codificação por temas.

Foram então construídas as categorias, a partir da leitura atenta que fez emergir aspectos centrais do estudo: a) O trabalho e suas arbitragens; b) A comunicação e o trabalho coletivo; c) $O$ uso do EPC e do EPI no beneficiamento a úmido. Apresentamos a seguir as análises e discussão dos dados e resultados. Optamos por inseri-los numa narativa que descreve a dinâmica da atividade coletiva em questão, em que se inscreve o recurso aos EPI's e o EPC analisados - realçando deste modo a complexidade dos seus usos.

46 Cabe esclarecer que os excertos utilizados são provenientes tanto de anotações de diários de campo, como também de entrevistas, indicadas no texto pela letra "E-", seguido do nome do trabalhador. 


\section{A Análise dos dados}

\subsection{0 trabalho e suas arbitragens}

47 Para atuar no beneficiamento de granitos os trabalhadores recebem treinamento por meio de cursos oferecidos [3] pela empresa, como meio de transmitir conhecimento sobre o trabalho no beneficiamento para os trabalhadores que nunca atuaram no setor, e também, como curso de reciclagem para os trabalhadores experientes. No que diz respeito à operação de ponte rolante, o curso é obrigatório para todas as etapas do beneficiamento de granito, inclusive as que utilizam a umidificação, e ministrado uma vez por ano por um técnico contratado pela empresa. Esse curso é a principal fonte de protocolos utilizada pelos trabalhadores que ingressam no setor de Rochas Ornamentais, além de tratar sobre a saúde e segurança no trabalho.

A percepção do trabalhador sobre sua área de trabalho é aqui enaltecida, considerando os riscos envolvidos nas atividades em análise. Riscos referentes à saúde e segurança no trabalho, uma vez que as atividades desenvolvidas englobam, dentre outras: movimentação de cargas pesadas com ventosas, cabos de aço, cintas, correias, correntes, garras, e faixas; equipamentos que geram poeira mesmo utilizando a água; e equipamentos que emitem ruído. Algumas falas evidenciam isso.

É muito perigoso, [..] nós corremos riscos a todo momento, devido a movimentação de cargas pesadas. Um vacilo que nós dermos e colocamos um membro em risco, por exemplo: a mão, o pé, é muito perigoso (E-Paulo).

[...] é um ambiente de muito perigo, e se acontecer alguma coisa com você, no outro dia você não volta a trabalhar, porque há o risco de acontecer acidente fatal (E-Matheus).

Sim é perigoso devido aos riscos de acidente, por exemplo: na ponte rolante, tem o risco do pacote de chapas cair, caso não pegue ele de modo correto. Além da poeira que gruda nos pulmões e não faz bem, causa silicose (ERodrigo).

O trabalho real, como enfrentamento de situações cotidianas de trabalho, na abordagem ergológica entende-se como um horizonte, nunca inteiramente circunscrito (Durrive \& Schwartz, 2008). A impossibilidade de descrevê-lo de modo fiel e exato é clara, dada sua complexidade e sua processualidade. Este é efetuado por indivíduos únicos e singulares, com sua história e experiências, desejos e expectativas, como enfrentamento de situações reais de trabalho, e expressa à dimensão dramática envolvida, com saberes e escolhas, que fazem história por criar situações novas não determinadas a priori (Schwartz, 2011b). Mesmo atuando em conformidade com as normas que regulamentam o setor, os trabalhadores entendem que estas não estão em conformidade com o dia-a-dia de trabalho, isto é, não tem total aderência com a atividade.

50 Conforme as normas, a realização de cursos antes do início do trabalho no setor é obrigatória. Na realidade, isso nem sempre ocorre, o que não deixa de poder contribuir para o aumento dos riscos relacionados à saúde e de possíveis acidentes, uma vez que o trabalhador pode desconhecer o que deve ou não ser realizado. Desse modo, o trabalhador realiza uso de si pelos outros ao observar o trabalho do outro e ter uma noção da prática sem ter realizado os cursos preparatórios obrigatórios no momento da admissão do trabalhador na empresa. Seguem alguns relatos. 
Basicamente não funcionam, é só na teoria, na prática não ocorre. [...] Às vezes a empresa não tem tempo para treinar o novo funcionário, e eu acho que antes de exercer a função a pessoa deveria ser treinada, no papel é assim, isso existe no papel, só que na prática não funciona. Se funcionasse, com certeza o novo funcionário iria pra a área de trabalho preparado e ciente que ele estaria em uma área de risco, mas eles vêm para a área sem saber nada, não sabem que é uma área tão perigosa. Se você fizer o curso você vai aprender e com seu aprendizado você vai tomar consciência daquilo, e vai acabar se policiando, agora, se você não faz o curso, não tem reciclagem, não tem uma preparação, você vai ficar a ver navios, vai ficar esperando ser a próxima vítima (E-César).

Quando eu entrei na empresa eu não tinha nenhum curso, e eu só poderia operar ponte com o curso, mas com o tempo eu fui observando e tendo uma noção de como fazia e comecei a operar ponte sozinho. Os patrões diziam que para operar ponte tinha que ter o curso, mas na função que eu trabalho tem que operar, então, na minha opinião isso é contra a norma, mas fazer o quê? $\mathrm{Eu}$ preciso trabalhar. Depois de alguns meses eu fiz o curso e aprendi as questões de segurança, de olhar ao redor e ter mais atenção, e eu não sabia disso antes do curso. Eu achava que operar ponte era só apertar o botão e já era, mas não é assim, tem que ter muito cuidado (E-Lucas).

51 Os trabalhadores reconhecem facilmente os Equipamentos de Proteção Individual, por serem divulgados nos cursos e/ou por serem de uso obrigatório e pessoal. No entanto, mesmo sendo de uso obrigatório, nem todos o utilizam, seja pelo fato deste incomodar durante a realização do trabalho, ou por entenderem que o EPI disponibilizado é inadequado para aquela atividade. Adiante, alguns relatos esclarecedores.

Uso o EPI direto, uso máscara, uso luva para empurrar a chapa na saída da máquina, mas quando vou mexer com água eu tiro a luva. Eu procuro sempre usar os EPI's, porque às vezes a pessoa prefere não usar ou usa quando o patrão chega, mas depois tira. Essa atitude prejudica a eles mesmos e não ao patrão. Às vezes é ruim usar, mas você sabe que no final evita muita coisa. 0 EPI é algo que ajuda há proteger um pouco, mas não impede que aconteça algo. Eu vejo muitos trabalhando sem usar a máscara, mas hoje você está novo, é quando chega numa certa idade que sente os efeitos (E-Adilson).

[...] uso o abafador, os óculos e a máscara. Às vezes não uso a máscara por causa da barba que impede de vedar a máscara. Eu uso os óculos de vez em quando porque cai pedra no olho. (E-Rodrigo).

Deveria mudar alguns EPI's, por exemplo: ao invés de óculos, poderia ter o capacete que tem a proteção para os olhos, como o do corpo de bombeiros, pois só os óculos embasa, e com a proteção do capacete não embasa, pode trabalhar tranquilo que não atrapalha (E-Lucas).

Desse modo, os trabalhadores arbitram ao utilizarem um ou outro EPI, mesmo que todos sejam de uso obrigatório. Trata-se de um uso de si pelos outros já que remete a um conjunto de regulamentos diversos, e que jamais se trabalha totalmente sozinho, mas com colegas de trabalho ou com pessoas não próximas (Schwartz, 2004; Schwartz et al., 2010a). Neste sentido eles também agem de acordo com as pressões, ou não, vivenciadas no momento da ação.

53 Por exemplo, na serragem, os trabalhadores atuam em local descoberto, isto é, fora do galpão onde estão localizadas as etapas do levigamento e do polilmento, ficando suscetíveis a intempéries como: chuva, sol, ventos fortes dentre outros, que influenciam também na realização da atividade e no uso dos EPI's. Ora, durante a 
vivência de campo foi possível constatar que nenhum trabalhador que atua no multifios utiliza o capacete, considerado um item de segurança, mas todos utilizam o boné como forma de proteção contra o sol.

[...] eu uso o abafador por causa do barulho, e uso boné por causa do sol, e a luva de lona quando vou mexer com a corrente da ponte rolante (E-Felipe). setores estudados. Enquanto os trabalhadores que atuam no levigamento e no polimento utilizam os óculos como forma de proteção contra respingos de água e pedaços de pedra que possam sair das máquinas, além da poeira, os trabalhadores da serragem utilizam os óculos, também, como proteção contra o sol. As falas mostram essa renormalização inscrita no uso dos equipamentos na atividade.

Aqui no setor nós usamos o EPI. Usamos o abafador e a máscara diariamente, além do óculos e do protetor solar por causa do sol, a gente se previne do jeito que dá (E-Thiago).

[...] de vez em quando eu uso o óculos, quando está quente (E-Felipe).

\subsection{A comunicação e o trabalho coletivo}

apa da serragem, para assentar o bloco no carro porta bloco [4], que se locomove por meio de trilhos no interior do maquinário do multifios, os trabalhadores fazem igualmente uso de si por si e pelos outros. Concretamente, há uso do corpo-si ao ajeitar a corrente do pórtico rolante $\left.{ }^{5}\right]$ ao bloco: à medida que movimentam o bloco e usam uma mão para segurar e precionar o botão do controle do pórtico para que este se movimente e a outra mão para apoiar e guiar o bloco, a fim de que ele fique parado e facilite a movimentação no pátio de estoque. Com esta finalidade, para lavar o bloco, Felipe usa o corpo à medida que manuseia a mangueira tomando cuidado para não molhar o parceiro Thiago, e empurra o bloco para fazer com que ele gire lentamente em seu eixo, já que está suspenso pela corrente e preso ao pórtico, porém, sem que ele se movimente para os lados e corra o risco de atingir alguém ou alguma máquina. Depois disso, usa as mãos e o peso do corpo para parar o bloco. E enquanto Felipe sai pela lateral do multifio puxando a mangueira para enrolá-la, Thiago, mais uma vez, com uma mão preciona o botão do controle do pórtico e com a outra vai guiando o bloco pela lateral do maquinário até chegar à parte de traz do multifio.

Podemos concluir que, para colocar o bloco em cima do carro, há uso do corpo-si desde o início: Thiago faz a movimentação do bloco por meio do controle, enquanto Felipe observa a alguns metros o enquadramento do bloco no carro e faz sinais com a mão e sonoro (ele assovia), para se comunicar com Thiago que está manuseando o controle do pórtico e juntos assentarem o bloco no carro porta bloco. Essa comunicação transforma o trabalho em algo conjunto, sollidário. Reconhecer e identificar as expressões linguageiras na atividade como uma criação e não como uma linguagem empobrecida é uma maneira extraordinária de reconsiderar a própria relação com o trabalho (Schwartz et al., 2010a).

Todavia, alguns trabalhadores da produção, são "conhecidos" pelos próprios colegas por não realizarem suas tarefas durante algum período do dia. Dito por eles: "dá um nó", fazendo com que certos trabalhadores fiquem mais sobrecarregados do que outros. No entanto, mesmo informando o encarregado dessas situações, elas persistem e 
desmotivam alguns trabalhadores justamente pelas situações não serem resolvidas. Aqui também, longe de ser uma espécie de registro empobrecido da linguagem, “dá um nó" possui um significado que acompanha a atividade humana de trabalho naquele contexto específico (Schwartz, 2010a). mesmo encarregado, não se intimida com as pressões da situação e se nega a carregar o cavalete de início do polimento, isso até que algum dos donos apareça no pátio para cobrar o motivo da máquina estar vazia. Com essa postura, o trabalhador realiza usos de si pelos outros - usos do corpo-si - ao deixar de carregar o cavalete, pois entende que está a favor do coletivo - há uma ponderação de valores e de noção de justiça nessa postura, uma vez que é uma tarefa acessória a função deste trabalhador e pode ser feita por ele ou pelos operadores de ponte. Em resumo, ao racionalizar, algo atravessa tanto o intelectual, o cultural, o fisiológico, o muscular e o sistema nervoso, que aliado a sua vivência e história na atividade de trabalho, o faz optar por agir desta maneira em tal situação, fazendo uso do corpo-si (Schwartz et al., 2010a), no caso ao não usar o corpo para dar visibilidade à situação. Deste modo, o trabalhador pode renormalizar o emprego do tempo de uma jornada de trabalho, hierarquizando à sua maneira as diversas tarefas - normas antecedentes - as quais se espera que ele realize, seguindo suas próprias normas com base na apreciação das dificuldades, da avaliação mais ou menos crítica do uso que se espera dele, e da preservação de seus recursos físicos e mentais.

61 Em relação à comunicação entre os sócios e os trabalhadores no dia a dia de trabalho esta, pelo que foi relatado, é aquém do que os trabalhadores esperam. De acordo com Adílson, que é um dos trabalhadores mais antigos na empresa, os patrões passam por eles durante a realização do trabalho e não falam nem bom dia e só param para conversar com os trabalhadores caso necessitem informar ou desejem receber alguma informação. Ao assumir essa postura, os patrões também realizam usos de si pelos outros (Schwartz et al., 2010a), uma vez que não dão atenção aos trabalhadores em si, acabam ferindo certos valores sociais dos mesmos, como se percebeu nesse relato.

Apelando ao uso, o sujeito pode recentrar (mesmo que no infinitesimal) o meio em torno de suas próprias normas, à medida que as renormalizações da atividade 
concernem a uma tentativa de sintetizar de modo coerente e em sinergia, todas as dimensões do ser como uma maneira pessoal de reagir e preencher a deficiência das normas e ordens, ressingularizando-as com sua história e seus valores na tentativa de viver o trabalho de forma saudável (Schwartz, 2014b; 2015). De acordo com Schwartz, Duc e Durrive (2010b) a motivação está na escolha e na articulação sempre um pouco bem sucedida, entre o uso de si por si e pelos outros, pois, caso contrário não haveria trabalho ou todos estariam doentes.

Os trabalhadores do levigamento atuam em local com muito barulho e poeira e por isso usam os EPI's, isto é, o protetor auricular e a máscara descartável. Mesmo com o barulho e o uso da máscara que interferem no volume da voz, isso não impede a comunicação, eles se comunicam por gestos e pelo olhar. Essas construções linguageiras são criações, mais ou menos bem ajustadas às situações de trabalho, e muitas vezes consideradas incompreensíveis, pois é concebida em razão das singularidades das situações (Schwartz, 2010b) e, mais uma vez, remetem ao uso do corpo-si.

Podemos lembrar aqui que, de acordo com Schwartz, et al. (2010b), a Entidade Coletiva Relativamente Pertinente (ECRP) diz respeito ao arranjo informal entre os trabalhadores, que se esforçam para recompor seu espaço de trabalho, sem necessariamente se falar, estabelecem um laço que remete ao compartilhamento de valores, e em certa medida, é responsável pelo ato eficaz.

Nesses termos, a percepção dos trabalhadores sobre o trabalho coletivo tem a sua especificidade, mas igualmente a sua variedade. Em relação ao trabalho coletivo no beneficiamento, há de fato entendimentos diversos - como também em relação ao trabalho da dupla, uma vez que todas as etapas do beneficiamento a úmido ocorrem com dois trabalhadores. Alguns entendem que há sentimento de grupo entre os trabalhadores do beneficiamento uma vez que há convivência e ajuda mútua, enquanto outros entendem que não, que a afinidade com uns e não com outros no trabalho se deve à convivência. Há aqueles que entendem que o sentimento de grupo se aplica a relação entre a dupla de trabalho e não com os demais trabalhadores do beneficiamento. A constituição das ECRP pode ser então associada a convivência cotidiana e a necessidade de ajuda mútua, tendo em vista o debate sobre as renormalizações a empreender na atividade, tal como podemos entender dos seguintes relatos:

Nós ajudamos uns aos outros, mas eu acho que não tem confiança, nem somos um grupo, eu tenho que ajudar o outro no serviço, eu vigio ele e ele me vigia para não acontecer nada de grave, é a convivência. (E-Maycon).

Eu e o Matheus trabalhamos juntos e nos ajudamos, é como se fosse uma família. Se eu vejo que ele precisa de ajuda, eu ajudo, e às vezes eu peço ajuda a ele, tem que ser unido, pois o trabalho passa a ser a nossa casa. Com os outros tem confiança devido à convivência, [...]. (E-Adílson).

Eu e o Rodrigo nos ajudamos, e não é porque eu ganho mais do que ele ou porque estou um grau mais alto do que ele que eu vou deixar ele se lascar, nós somos uma equipe: eu e ele, ele e eu, e eu vou lá e ajudo ele, ele vem e me ajuda e o serviço flui. Mas fora isso a turma não se ajuda, ás vezes eu estou laçando um pacote e a pessoa passa perto, ela sabe que pode te ajudar, mas vira as costas e vai embora. Não há sentimento de grupo, o trabalho em equipe não existe, deveria existir, deveria ser cobrado, eu acho que pela a empresa ser pequena deveria existir esse trabalho em equipe, um ajudando o outro, e isso seria legal e uma forma de sermos mais amigos, mas não temos 
isso aqui, [...] as pessoas são muito individuais, é cada um para si, Deus para todos, e você que se vire para lá. (E-César). de "família" que surge com o tempo. A necessidade de ajuda mútua é tida como o fator responsável por se trabalhar de modo que "eu vigio ele e ele me vigia", fazendo uso do corpo-si numa vigília em prol da saúde e segurança, de modo que cada trabalhador não trabalha apenas para si, mas um pelo outro, tendo como produto a união das duplas de trabalho, e em certo grau, a união dos trabalhadores do beneficiamento. Falar do "saber trabalhar em equipe", não é uma expressão apropriada (Schwartz, 2010b), uma vez que os fatores que podem garantir o bom trabalho em equipe dependem de cada coletivo específico e surge das interações dos atributos prévios da pessoa com esse coletivo, algo que não pode ser exigido, identificado ou avaliado previamente (Holz, 2014).

\subsection{0 uso do EPC e do EPI no beneficiamento a úmido}

No beneficiamento a úmido, a água é utilizada para minimizar a dispersão de poeiras. Mas, se os trabalhadores entendem que o uso da água está relacionado ao trabalho coletivo, raramente o relacionam com um EPC - cujo entendimento, aliás, varia.

O EPC eu não conheço, nunca ouvi falar (E-Adilson).

Sobre o EPC eu já ouvi falar, mas a gente nunca chegou a esse ponto aqui na empresa (E-César).

O EPC protege não só a mim, mas como as outras pessoas da empresa, até mesmo as pessoas que vem nos visitar, por exemplo: as placas de sinalização, as demarcações no chão (E-Paulo).

$\mathrm{O}$ uso da água no beneficiamento de granitos contribui para melhorias no ambiente de trabalho, como a prevenção de doenças respiratórias, por minimizar a dispersão de poeiras, conforme os aspectos normativos ressaltam. E colabora, também, para o resultado do produto final do beneficiamento, ou seja, das chapas de mármore ou granito: porque a água auxilia no resfriamento dos fios diamantados da serragem, utilizados no maquinário multifios, e no resfriamento dos abrasivos utilizados para levigar e polir as chapas. Neste caso é um agente técnico do processo, conforme referido nas falas a seguir.

A água ajuda em tudo [...] porque a água tem que estar na chapa para o satélite rodar e não pegar fogo, porque, mesmo com água às vezes saem faíscas. Eu acho que se não tivesse a água, a máquina não iria funcionar. A importância de usar a água é devido ao pó (como se fosse vapor) que sai da máquina, porque sempre que acaba a água, porque às vezes ela tranca, e a máquina fica rodando, não é possível ver a pessoa que está do outro lado, de tanta poeira. Isso prejudica a minha saúde e a das pessoas ao redor, por que espalha pelo ar. Se não tivesse a água eu nem sei o que seria de nós dentro daquele galpão (E- Matheus).

Sem água não tem como polir, porque não tem como tirar a resina só com o abrasivo, tem que ter a água para evitar a poeira, ajuda a resfriar o contato entre o abrasivo e a chapa, e se fizer muita poeira não tem como trabalhar (E-Lucas).

A água ajuda bastante [...] ela reduz a poeira, e sem ela não teria como trabalhar, porque tem que resfriar os fios para serrar (E-Maycon). 
69 auxiliando na diminuição dos riscos vinculados a determinadas atividades do trabalho, isto é, atuando como um EPC.

Todavia, a água utilizada nos processos de produção da serragem, do levigamento e do polimento é reaproveitada, isto é, reutilizada após ser tratada. Segundo os relatos obtidos, isso traz consequências para a saúde dos trabalhadores, uma vez que esta água acaba por possuir resíduos minerais das pedras, produtos químicos utilizados para limpeza das máquinas, resíduos da resina que é retirada das chapas e dos produtos utilizados para limpeza da água na estação de tratamento. Pode então gerar irritação da pele e nos olhos devido ao contato, ou seja, caso ela atinja os olhos ou fique em contato por muito tempo com a pele. Em meio a essas condições materiais de trabalho, os trabalhadores mobilizam, mais uma vez, o uso de si pelos outros e se previnem como podem contra os riscos que a água reaproveitada pode gerar a sua saúde. Fato que reitera a importância da utilização dos EPI's como forma de proteção.

\begin{abstract}
[..] quando faz poeira o galpão todo fica cheio, e o nosso setor como qualquer outro setor da empresa é prejudicado, a água é essencial para todos, e se não tiver a água não tem como trabalhar. Mas como a água é reaproveitada e tem produto químico, por exemplo: o ácido que nós usamos para limpar a máquina, tem que jogar o ácido e usar a luva para lavar, porque se tiver contato direto com a pele a mão fica em carne viva, e esse ácido vai junto com a água para ser reciclada. [...] Eu já tive alergia na pele por estar em contato com a água do polimento, e irritação no olho porque um dia respingou água da máquina no meu olho (E-Lucas).
\end{abstract}

Por isso, mesmo que em falas anteriores os trabalhadores tenham reconhecido a importância da água, e de vivenciarem seu uso como proteção ao minimizar a dispersão de poeiras, no relato acima Lucas faz perceber que o uso da água não traz somente benefícios, mas também traz riscos por conter produtos químicos. Nesse sentido, em que medida o uso da água pode ser concebida enquanto proteção? O fato dos trabalhadores não associarem o uso da água a um EPC pode, de fato, estar relacionado a essa vivência: não se trata de qualquer água, mas desta, que é reaproveitada e que retorna ao trabalhador contendo impurezas.

Diante das situações de trabalho, situações paradoxais, que envolvem escolhas, imposições, decisões e renuncias individuais e coletivas, o trabalhador, engajado em sua atividade, por vezes, se deixa levar pelas imposições do meio como por exemplo: na falta de EPI's que favoreçam a atividade de trabalho, deixando de usá-los também pelo descaso dos demais colegas em estar utilizando os EPI's, às vezes, por preguiça ou esquecimento, criando a sensação de que não é necessária a sua utilização pelos demais. Porém, por mais que a empresa, ou o coletivo de trabalho, não incentive ou promova uma ação, o indivíduo decide o que deve ou não fazer com base, também, em sua história de vida, sua vivência, seus valores.

Adilson, por exemplo, que trabalha há anos na empresa, por morar distante, necessita acordar todos os dias às 04:00 horas da manhã para ir trabalhar e só chega em casa às 22:00 horas, possui baixa escolaridade, no entanto passou por vários setores na empresa ao longo de 12 anos: atualmente, é o único trabalhador, em toda a empresa, que utiliza o capacete. Isso porque já sofreu um acidente no passado que poderia ter sido minimizado ou até evitado caso estivesse usando o capacete. Quando teve a 
oportunidade de ter de usar o capacete, ele o fez e continua a fazer. O que ele diz está a seguir.

Aquela pinça que pega as chapas já caiu em mim, você pode olhar e ver que meu nariz é torto, era à noite, eu ajeitei a chapa para pegar com a pinça e o cabo de aço quebrou e ia bater na minha cabeça, eu vi e virei o rosto, nisso ela bateu no meu nariz e quebrou, mas eu continuei trabalhando assim mesmo, e nunca fui ao médico. [...] Há algum tempo atrás, o menino caiu e machucou a cabeça, depois disso inventaram que todos tinham que usar o capacete, e desse dia em diante compraram capacete para todo mundo, antes não tinha. Com isso, usaram umas duas semanas e foram largando e o único que está usando até hoje sou eu (E-Adilson).

Devido a sua história singular, sua vivência de um corpo que sofreu um acidente, e sua ética do trabalho inscrita no corpo-si - a entidade que atravessa o intelectual, o cultural, o fisiológico, o muscular, o sistema nervoso e racionaliza (Schwartz et al., 2010a), Adílson se comporta de modo distinto dos outros trabalhadores do beneficiamento a úmido. Diante de situações em que os outros trabalhadores se abstêm do uso do EPI, numa atitude de "deixar para lá", ele não se acomoda e incentiva os outros colegas de trabalho, inclusive de outros setores, a utilizarem os EPI's.

Se eu vejo os meninos lixando chapa sem usar a máscara, eu aviso para eles colocarem, porque hoje você não sente nada, mas daqui um tempo. Às vezes eu vejo os rapazes resinando sem a máscara e eu aviso eles para usarem, e na hora eles colocam, acho que é porque eu sou mais velho. Eu sempre falo, porque eu sei que vai prejudicar. Tem uns que só usam quando o patrão está perto, mas eu falo para eles que o abafador, por exemplo, protege ele e não o patrão, mas o patrão cobra porque se o ministério do trabalho chegar, vai cobrar dele. No começo eu falava com o Matheus que trabalha comigo e ele não queria usar o abafador e a máscara, mas de tanto eu falar, agora ele usa sempre. Às vezes a pessoa pega o abafador e coloca na cabeça, ai eu digo que ele tem que proteger o ouvido e não o chifre (E-Adilson).

75 A escolha de se proteger com ou sem EPI's, ou com EPI's inadequados, se constitui em atividade em si. Os trabalhadores contribuem para a mobilização do uso de si por si $e$ pelos outros no que tange a utilização destes equipamentos, ao contemplar as dimensões singulares do trabalho humano, convocando corpo, psiquismo e pensamento a mudar, no sentido de criarem suas normas e viverem em conformidade com elas (Canguilhem, 1995).

\section{Considerações Finais}

O presente estudo, além de pontuar diversos aspectos da realidade do trabalho na organização e, no que diz respeito à saúde e segurança na atividade de trabalho no setor, trouxe dados que falam por si só, ao mostrar que o prescrito, as normas antecedentes não dão conta de prever o real. As arbitragens diante de um meio que desafia são assumidas pelo corpo-si. Ou seja, o uso de si se manifesta pelo corpo em atividade no beneficiamento de granitos - envolvendo todos os aspectos, biológicos, físicos, sociais, culturais e valores. Valores esses que se estabelecem numa ética coletiva da vivência naquele meio de trabalho e não em outro. Pautado pelo macro em coadunação com o micro da atividade. Pautado pelo clima do dia, pela dupla de trabalho em atividade, no seu agir conjunto e solidário. E, muitas vezes também no seu 
agir mais solidário e inserido no coletivo que os permeia, impregnado de valores do meio, dos riscos eminentes - riscos de e riscos por - dos encontros a serem geridos.

$\mathrm{O}$ artigo se propôs a compreender usos de si por si e pelos outros, usos do corpo-si e diferentes renormalizações do trabalho nos processos de umidificação do beneficiamento de granitos, trazendo evidências desse uso para um possível diálogo entre o polo dos saberes investidos na atividade e o polo dos saberes concetuais, académicos. Mostrou a falta de adequação ao uso dos EPI`s, para possibilitar condições dignas de trabalho, e promover a saúde e segurança dos trabalhadores, bem como as renormalizações atribuídas a esses usos. Trouxe elementos da vivência do uso da água de modo paradoxal, como proteção e como risco, levando a novas reflexões sobre as limitações do uso dessa água reaproveitada nos processos a úmido, para tal ser concebida efetivamente como uma proteção. Elementos que contribuem diretamente no entendimento, ou não, pelos trabalhadores do uso da água como um EPC.

Os usos do corpo-si com ou sem EPI's ou EPC possibilita ao trabalhador identificar alternativas para dar resposta ao que o real da atividade confronta (Moraes \& Pinto, 2011), ao ser, constantemente, confrontado com variabilidades ao realizar suas tarefas. Isto é, o uso do conceito de corpo-si pode contribuir para compreensão dos riscos do trabalho por escolha coletiva decorrente do viver junto, que traz consigo a história de cada um (Schwartz, 2014b).

Além disso, o presente estudo poderá auxiliar na valorização do conceito de atividade no campo da gestão da saúde e segurança. Do reconhecimento do que, Schwartz (2014b) traz como risco do trabalho e da importância do conceito de corpo-si para lidar com isso. Compreender o trabalho para se pensar novas ações de prevenção à saúde e segurança, não esquecer que o uso dos equipamentos de protecção constitui uma atividade em si e exige levar em conta os saberes e experiências dos trabalhadores com base em suas atividades, parece um caminho oportuno para obtenção de melhores resultados organizacionais e sociais num setor - de rochas ornamentais - permeado por acidentes e condições de trabalho questionáveis tanto no Estado do Espírito Santo como no Brasil.

\section{BIBLIOGRAFIA}

Ayub, A. L., Ferreira, C., Martins, F., Machado, L. L., Baptista, N., Moura, R., Rocha, S., \& Lourenço, T. (2014). Anuário IEL 200 Maiores Empresas: Espírito Santo, edição 2014, IEL: 2015, p.60-61. Retirado abril, 10, 2015 de http:// issuu.com/nexteditorial/docs/anuario

Bardin, L. (2006). Análise de conteúdo. Lisboa: Edições 70.

Binda, J. (2009). Projeto de Uma Cartografia do trabalho dos agentes Comunitários de Saúde da Ilha das Caieiras. Dissertação de Mestrado em Administração, Universidade Federal do Espírito Santo, Vitória.

Canguilhem, G. (1947). Milieu et normes de l'homme au travail. Cahiers Internationaux de Sociologie, 3, 120-136. 
Canguilhem, G. (1994). Etudes d'histoire et de philosophie des sciences. Paris: Vrin.

Canguilhem, G. (1995). o Normal e o Patológico. $4^{\text {a }}$ Edição. Rio de Janeiro: Forense Universitária.

Cattabriga, 1., \& Castro, N. F. O. (2013). Saúde e Segurança no trabalho. In F. W. H. Vidal, H. C. A. Azevedo e N. F. Castro (Ed.), Tecnologia de Rochas Ornamentais: Pesquisa, Lavra e Beneficiamento (pp. 399-432). Rio de Janeiro: CETEM/MCTI.

Chiodi, D, K. (Ed.) (2015, Jan./Mar.). ABIROCHAS em Notícia: Brasil é destaque no mercado internacional de rochas ornamentais. Retirado outubro, 7, $2015 \mathrm{de} \mathrm{http://issuu.com/abirochas/docs/}$ abirochas_em_noticia_1.

Deleuze, G. \& Guattari, F.(1995). Mil Platôs, vol. 1. Rio de Janeiro: Editora 34.

Duraffourg, J., Duc, M., \& Durrive, L. (2010). O trabalho e o ponto de vista da atividade. In Y. Schwartz e L. Durrive (Org.),Trabalho \& Ergologia: conversas sobre a atividade humana (pp.47-87). Niterói: EdUFF.

Durrive, L. (2010). Pistas para o ergoformador animar os encontros sobre o trabalho. In Y. Schwartz e L. Durrive (Org.), Trabalho \& Ergologia: conversas sobre a atividade humana (pp.309-318). Niterói: EdUFF.

Durrive, L., \& Jacques, A. M. (2010). o formador ergológico ou "Ergoformador": uma introdução à ergoformação. In Y. Schwartz e L. Durrive (Org.), Trabalho \& Ergologia: conversas sobre a atividade humana (pp. 295-307). Niterói: EdUFF.

Durrive, L., \& Schwartz, Y. (2008). Glossário da Ergologia. Laboreal, 4, (1), 23-28. http:// laboreal.up.pt/revista/artigo.php?id=48u56oTV6582234396587;63882

Gruenzner, G. (2003). Avaliação da Poeira de Sillica: Um Estudo de Caso em uma pedreira na Região Metropolitana de São Paulo. Dissertação de Mestrado em Engenharia Mineral, Escola Politécnica, Universidade de São Paulo, São Paulo.

Holz, E. (2014). O Trabalho e a Competência Industriosa no Beneficiamento de Granitos: Uma Cartografia Ergológica. Dissertação de Mestrado em Administração, Universidade Federal do Espírito Santo, Vitória.

Kastrup, V. (2009). O funcionamento da atenção no trabalho do cartógrafo. In E. Passos, V. Kastrup e L. Escóssia (Orgs.), Pistas do método da cartografia: pesquisa-intervenção e produção de subjetividade (pp.32-51). Porto Alegre: Sulina.

Mendes, R. W. B. (2014). Apropriação Sistêmica de Inovações Tecnológicas para a Prevenção: o Caso do Controle de Poeira em Mineradoras de Granito. Tese de Doutorado em Engenharia de Produção, Universidade Federal do Rio de Janeiro: Rio de Janeiro.

Mezadre, S. B. B. (2013). o Polimento dos Saberes: Um Estudo de Situações de Trabalho em uma Empresa Beneficiadora de Mármore e Granito. Dissertação de Mestrado em Administração, Universidade Federal do Espírito Santo, Vitória.

Moraes, T. D., \& Pinto, F. M. (2011). O corpo nas atividades em trânsito: condutores profissionais e mobilização do corpo-si. Cadernos de Psicologia Social do Trabalho, 14, 2, 279-294.

Neves, M. Y., Athayde, M., \& Muniz, H. P. (2004). Notas sobre saúde mental e trabalho docente a partir de uma investigação com professoras de escolas públicas. In M. Figueiredo et al. (Orgs.), Labirintos do trabalho: interrogações e olhares sobre o trabalho vivo (pp.302-321). Rio de Janeiro: DP\&A.

Ribeiro, F. S. N. (Coord.) (2010). o mapa da exposição à sílica no Brasil/ Coordenação Geral Fátima Sueli Neto Ribeiro. Rio de Janeiro: UERJ, Ministério da Saúde. 
Rolnik, S. (2006). Cartografia sentimental: transformações contemporâneas do desejo. Porto Alegre: Sulina, Editora da UFRGS.

Santos, A. M. A., Cançado, R. Z. C., Anos, R. M., Amaral, N. C., \& Lima, L. C. A. (2007).

Características da exposição ocupacional a poeiras em marmorarias da cidade de São Paulo. Revista Brasileira de Saúde Ocupacional, 32, 116, http://www.scielo.br/scielo.php? script=sci_arttext\&pid=S0303-76572007000200003\&lng=pt\&nrm=iso\&tlng=en

Schwartz, Y. (1998). Os Ingredientes da competência: um exercício necessário para uma questão insolúvel. Educação \& Sociedade, 19, 65, 101-140.

Schwartz, Y. (2000). Trabalho e uso de si. Revista Pro-posições, Faculdade de Educação, Unicamp, 32. São Paulo.

Schwartz, Y. (2004). Circulações, dramáticas, eficácias da atividade industriosa. Trabalho, Educação e Saúde, 2, 1, 33-55.

Schwartz, Y. (2010a). A trama e a Urdidura. In Y. Schwartz e L. Durrive. (Orgs.), Trabalho \& Ergologia: conversas sobre a atividade humana (pp. 103-109). Niterói: EdUFF.

Schwartz, Y. (2010b). Uso de si e competência. In Y. Schwartz e L. Durrive. (Orgs.), Trabalho \& Ergologia: conversas sobre a atividade humana. (pp. 205-221). Niterói: EdUFF.

Schwartz, Y. (2011a). Conceituando o trabalho, o visível e o invisível. Revista Trabalho, Educação e Saúde, 9, supl.1, 19-45.

Schwartz, Y. (2011b). Manifesto por um ergoengajamento. In P. F. Bensassolli e L. A. P. Soboll (Orgs.), Clínicas do Trabalho: Novas perspectivas para compreensão do trabalho na atualidade (pp. 132-166). São Paulo: Atlas.

Schwartz, Y. (2014a). Motivações do conceito de corpo-si: corpo-si, atividade, experiência. Letras de Hoje, 49, 3, 259-274.

Schwartz, Y. (2014b). O Enigma do Trabalho: riscos profissionais e riscos do trabalho. In M.

F.BIANCO (Coord.). Competências e Gestão: dialogando com o trabalho e decifrando suas conexões (pp. 59-70). Vitória: PROEX/UFES.

Schwartz, Y. (2015). Conhecer e estudar o trabalho. Trabalho \& Educação. Belo Horizonte, 24, 3, p. 83-89.

Schwartz, Y., Duc, M., \& Durrive, L. (2010a). Trabalho e Ergologia. In Y. Schwartz e L. Durrive. (Orgs.), Trabalho \& Ergologia: conversas sobre a atividade humana (pp.25-360). Niterói: EdUFF.

Schwartz, Y., Duc, M., \& Durrive, L. (2010b). Trabalho e Uso de Si. In Y. Schwartz e L. Durrive. (Orgs.), Trabalho \& Ergologia: conversas sobre a atividade humana (pp.189-204). Niterói: EdUFF. Vitoriastonefair. (2015). O setor. Retirado fevereiro, 12, 2015 de http:// www.vitoriastonefair.com.br/site/2015/pt/setor.

Weber, L., Grisci, C. L. I., \& Paulon, S. M. (2012). Cartografia: aproximação metodológica para produção do conhecimento em gestão de pessoas. Cadernos EBAPE, 10, 4, 841-857.

\section{NOTAS}

1. Interpreta-se o uso da água como um dispositivo ou equipamento de proteção coletivo (EPC), cujo uso de acordo com a norma técnica prevê proteger a todos que estão submetidos à poeira do ambiente produtivo. Trabalhadores, membros do Sindicato dos trabalhadores do mármore e 
granito no Estado já entendem este uso da água como EPC, conforme dados obtidos em pesquisas anteriores realizadas pelo grupo de pesquisa.

2. Número de empregos diretos gerados pelo setor de beneficiamento de mármore e granito no sul do Espírito Santo: 4.320 empregos em 2012 (Mezadre, 2012).

3. Os cursos oferecidos são: o curso de operador de ponte rolante e o de manutenção e operação de máquinas, ambos obrigatórios e alvo de fiscalização do Ministério do Trabalho e Emprego.

4. Equipamento para a movimentação dos blocos de mármore e granito.

5. Equipamento para movimentação e elevação de blocos.

\section{RESUMOS}

A análise ergológica é desenvolvida, tanto quanto possível, privilegiando o ponto de vista da atividade e com o intuito de evidenciar o debate de normas e de valores que em permanência renovam a atividade humana. A pesquisa foi conduzida numa empresa de transformação de granito do Estado do Espírito Santo, no Brasil. O objetivo consistiu em compreender os usos do corpo-si, tal como se configuram na tentativa de preservação da saúde e da segurança, no contexto dos processos de umidificação, associados ao tratamento do granito. Partindo do acompanhamento de processos concretos de trabalho - e assumindo a postura de um cartógrafo, através da exploração dos dados recolhidos no âmbito de um diário de campo, bem como no contexto de entrevistas conduzidas com dez trabalhadores - o estudo revelou exemplos de modos de uso do corpo-si na gestão da saúde e da segurança, na atividade em análise. Tornou-se visível um recurso inapropriado dos EPI's à disposição, e a ausência de consciência das potencialidades decorrentes dos equipamentos de proteção coletiva (EPC), comprometendo-se desta forma o acesso a condições de trabalho dignas, e a preservação da saúde e segurança dos trabalhadores.

El análisis ergológico se desarrolla, en la medida de lo posible, favoreciendo el punto de vista de la actividad y con objeto de poner de relieve la discusión de las normas y valores que renuevan continuamente la actividad humana. La investigación se realizó en una empresa de procesamiento de granito en el estado de Espírito Santo, Brasil. El objetivo fue comprender los usos del cuerpo-sí, tal como se configuran en el intento de preservar la salud y seguridad, en el contexto de los procesos de humidificación asociados con el tratamiento de granito. A partir del seguimiento de procesos de trabajo concretos - y asumiendo la postura de un cartógrafo, a través de la explotación de los datos recogidos en un diario de campo, así como en el contexto de entrevistas realizadas con diez trabajadores - el estudio encontró ejemplos de modos de uso del cuerpo-sí en la gestión de la salud y la seguridad, en la actividad bajo análisis. Se observó un uso inadecuado de los EPP disponibles y la falta de conciencia del potencial derivado de los equipos de protección colectiva (EPC), comprometiéndose así el acceso a condiciones dignas de trabajo y la preservación de la salud y la seguridad de los trabajadores.

L'analyse ergologique est menée, autant que possible, en privilégiant le point de vue de l'activité et avec l'intention de mettre en évidence le débat de normes et de valeurs qui la renouvelle sans cesse. La recherche a été menée dans une entreprise de transformation de granit de l'État de Espirito Santo, au Brésil. L'objectif était de comprendre les usages du corps-soi lorsqu'ils se définissent en vue d'une sauvegarde de la santé et de la sécurité, au cours de procédés d'humidification dans le traitement du granit. Sur base d'un suivi des processus concrets de 
travail - et en assumant la posture d'un cartographe, en exploitant également les données reprises dans un journal de bord ainsi que celles recueillies lors des entretiens avec 10 travailleurs, l'étude a illustré quelques modes d'usages du corps sur ces plans de la santé et la sécurité, dans l'activité en question. On a ainsi mis en évidence un recours inapproprié des EPI mis à disposition et l'absence de conscience des potentialités de procédés relevant de l'équipement de protection collectif (EPC), empêchant de cette façon que soient réunies des conditions de travail dignes, ne mettant pas en cause la santé des travailleurs.

The ergological analysis is developed, as far as possible, privileging the activity's point of view in order to emphasise the debate about norms and values that renew the human activity on a regular basis. The research took place in a granite processing firm in the State of Espírito Santo, in Brazil. The objective of the research was to understand the body-oneself uses, considering them as taken in the attempt to preserve health and safety, in the humidification processes related to granite treatment. Based on the monitoring of the actual work processes - and assuming the posture of a cartographer, through the exploration of the data collected under the scope of a field diary and in the context of the interviews conducted with ten workers - the study revealed examples of body-oneself uses in the health and safety management, in the activity under analysis. It brought to light the inappropriate resource of the available PPE and the lack of awareness regarding the potential use of the collective protection equipment (CPE), hence compromising the access to dignified working conditions and the preservation of the workers' health and safety.

\section{ÍNDICE}

Palabras claves: procesos de trabajo, ergología, salud y seguridad, procesamiento de granito Keywords: work processes, ergology, health and safety, beneficiation of granites Mots-clés: processus de travail, ergologie, santé et sécurité, exploitation du granit Palavras-chave: processos de trabalho, ergologia, saúde e segurança, beneficiamento de granitos

\section{AUTORES}

\section{THIARA DE ÂNGELI PORTO}

Programa de Pós-Graduação em Administração, Centro de Ciências Jurídicas e Econômicas, Universidade Federal do Espírito Santo, Av. Fernando Ferrari, 514, Goiabeiras, CEP: 29075-910, Vitória - Espírito Santo, Brasil

thideangeli@gmail.com

\section{MÔNICA DE FATIMA BIANCO}

Grupo de Estudos em Trabalho Ergologia e Gestão (GETERGE), Centro de Ciências Jurídicas e Econômicas, Departamento de Administração, Universidade Federal do Espírito Santo. Av. Fernando Ferrari, 514, Goiabeiras, CEP: 29075-910, Vitória - Espírito Santo, Brasil mofbianco@gmail.com 